\begin{tabular}{|l|l|l|l|}
\hline PUCRS & HUMANIDADES & $\begin{array}{l}\text { Conversas \& Controvérsias, Porto Alegre, v. 7, n. 1, p. 1-10, jan.-jun. 2020 } \\
\text { e-ISSN: 2178-5694 }\end{array}$ \\
\hline Inttp://dx.doi.org/10.15448/2178-5694.2020.1.35482 & \\
\hline
\end{tabular}

SEÇÃO: ARTIGO LIVRE

\title{
Participação popular no Brasil: uma análise sobre plebiscito, referendo, iniciativa popular, recall e veto popular
}

\author{
Popular participation in Brazil: an analysis of the plebiscite, referendum, popular \\ initiative, recall and popular veto
}

\section{Bruna Hamerski ${ }^{1}$ orcid.org/0000-0003-2029-394X bruh_hamerski@hotmail.com}

Recebido em: 1 set. 2019 Aprovado em: 30 mar. 2020. Publicado em: 17 set. 2020.

\section{(c) (1)}

Artigo está licenciado sob forma de uma licença Creative Commons Atribuição 4.0 Internacional.
Resumo: O artigo visa demonstrar o nivel de participação popular no caso brasileiro, a respeito dos instrumentos plebiscito, referendo, iniciativa popular, recall e veto popular, sob a perspectiva da teoria de Sherry Arnstein. Parte-se do pressuposto da importância de práticas de gestão participativa vinculantes, onde se possa verificar de forma concreta a participação popular. Em termos metodológicos, foi realizada a análise de conteúdo da regulamentação dos instrumentos de participação. Posteriormente, foi investigado em que degraus da escala de participação se encaixam os instrumentos. Os resultados demonstram um déficit democrático, tendo em vista que os instrumentos vigentes não se enquadram em degraus superiores da escala de participação. Conclui-se que a Participação Popular ainda necessita passar por muitos avanços, tanto por parte da sociedade civil quanto por parte do Estado, no sentido de regulamentação de práticas mais eficazes de controle social e ambiciosas do ponto de vista da Participação Popular.

Palavras-chave: Controle Social. Democracia. Participação Popular. Cidadania.

Abstract: This paper aims to demonstrate the level of Popular participation in the Brazilian case, in respect to the plebiscite instruments, references, popular initiatives, recall and popular veto, from the perspective of Sherry Arnstein's theory. It assumes the importance of binding participatory management practices, where it is possible to verify in a solid way the popular participation. In methodological terms, content analysis was performed, based on the instruments of participation. Subsequently, it was investigated in which levels of the participation scale the instruments fit in. The results demonstrate a democratic deficit, considering that the present instruments do not fit in the upper level of the participation scale. It is concluded that Popular Participation can still go through several advances, both on the part of Civil Society and on the part of the State, in the sense of regulamentation of more practical practices of social control and ambitious in the point of view of Popular Participation.

Keywords: Social Control. Democracy. Popular participation. Citizenship.

\section{Introdução}

A temática da Participação Popular e as relações entre técnica e política têm ganhado grande centralidade nas últimas décadas, sobretudo no caso brasileiro. Em parte, dado o processo de transformação societária em que se verificou o aumento do interesse da população pelo tema. Ademais, pelos desafios que se colocam aos governos, por prestação de serviços de qualidade e entrega de políticas públicas eficazes para a população. 
Do ponto de vista teórico, múltiplas visões sobre participação permeiam esse campo, com perspectivas que ora se aproximam, ora se mostram opostas. Por um lado, defende-se um modelo representativo, onde os indivíduos elegem seus representantes (Dahl 2001; Tocqueville 2005). Igualmente, argumenta-se que o aumento da participação direta pode levar ao totalitarismo, alegando que o cidadão comum não deve "agir" e sim "reagir" às iniciativas políticas dos rivais (Sartori 1962 citado por Pateman 1992). De outra banda, argumenta-se que a principal função da participação em uma teoria democrática é educativa: quanto mais os individuos participam, melhor capacitados eles se tornam para fazê-lo (Pateman 1992).

No caso brasileiro, a Participação Popular se estabelece do ponto de vista formal, com a Constituição Federal de 1988, preconizando o Estado Democrático de Direito e estabelecendo o sufrágio universal e o voto direto e secreto como formas de exercer a soberania popular, através do plebiscito, do referendo e da iniciativa popular (Brasil 1988). Apesar de não referidos na Constituição Federal de 1988, o veto popular e o recall também são considerados de extrema relevância para o presente estudo e serão citados posteriormente, tendo em vista que já foram objeto de Projetos de Lei em determinados contextos históricos, apesar de não terem sido implementados.

Em vista disso, o artigo quer chamar atenção para a importância da participação e do controle social como elementos centrais para a tomada de decisão, atentando para a participação idealizada na Constituição Federal de 1988: "participação da população [...] na formulação das políticas e no controle das ações em todos os niveis" (Brasil 1988).

Assim, considera-se a Participação Popular, em caráter deliberativo, como eixo central no que se refere à tomada de decisão e à elaboração de políticas públicas eficazes e que atendam às demandas da população. Carole Pateman (1992) já mencionava a necessidade de expansão da participação, propondo um modelo que exigia transformações profundas. Porém, com a década de 1990, tem-se uma redução de ambições, onde o foco é a distribuição do investimento público, não interferindo nas fronteiras que separam o Estado da Sociedade Civil.

Considerando o que foi introduzido, tem-se como objetivo principal analisar os instrumentos de participação preconizados na constituição, plebiscito, referendo, iniciativa popular, recall e veto popular, fazendo a tentativa de demonstrar em que nivel de participação da sociedade civil se enquadram. Em termos teóricos, partiu-se, como ponto principal, da teoria da autora Sherry Arnstein, que trata das escalas de participação e de autores da democracia contra-hegemônica, que aborda a Participação Popular direta. Em termos metodológicos, partiu-se de pesquisa bibliográfica, a respeito dos dispositivos legais que tratam da Participação Popular no Brasil para, posteriormente, realizar a demonstração do nivel de participação, em relação às escalas propostas por Sherry Arnstein.

Para dar conta dos objetivos, nas páginas que seguem, discorrer-se-á sobre a construção teórica a respeito do tema, utilizando teorias que se mostram pertinentes do ponto de vista conceitual, para analisar a questão da participação.

\section{Do modelo representativo à participação direta: uma descrição de teorias democráticas}

O conceito de democracia e participação é objeto de uma grande disputa no campo da Ciência Política, sendo objeto de diversas contestações doutrinárias. Tal afirmação se centra no fato de que existem dois tipos de democracia: a hegemônica (dominante na atualidade) e a contra-hegemônica. A democracia hegemônica nos dias atuais é a democracia liberal, cujo modelo se sustenta basicamente na representação, na formalidade, no modelo indireto.

Desse modo, a democracia hegemônica se associa, sobretudo, à questão do voto. Como exemplos de autores adeptos à democracia hegemônica, pode-se citar Alexis de Tocqueville (2005) e Robert Dahl (2001).

Tocqueville é um defensor do modelo representativo, defendendo o modelo norte-americano, no qual o povo participa da composição 
das leis pela escolha dos legisladores e de sua aplicação pela eleição. Através desse modelo, o povo nomeia o criador da lei e seu executor. Assim, o autor argumenta que o povo é quem nomeia diretamente seus representantes e é o povo quem os escolhe, com o objetivo de mantê-los em sua dependência (Tocqueville 2005).

Robert Dahl também é um grande defensor do modelo representativo, ao definir como critério essencial de uma democracia a igualdade no voto. Para ele, todos os cidadãos devem ter a mesma oportunidade de votar, sendo todos os votos contados com o mesmo peso, defendendo uma certa frequência nas eleições para os representantes do legislativo, onde eleições anuais seria um exagero, mas eleições a cada cinco anos seria um intervalo muito longo (Dahl 2001, 109-110).

Entretanto, os autores que defendem a Participação Popular como um mecanismo que se estende para além do voto, que é o principal foco do presente trabalho, são os autores adeptos da democracia contra-hegemônica. Por esse motivo, cabe mencionar os autores adeptos dessa teoria democrática, citando Rosa Luxemburgo (1991), Carole Pateman (1992), Ellen Wood (2003), Carlos Estevam Martins (2004) e Domenico Losurdo (2004). Tais autores possuem foco central para o presente estudo, considerando que os tipos ideais de participação defendidos pela democracia contra-hegemônica pregam a Participação Popular direta, em caráter deliberativo, que consiste no eixo central da presente pesquisa.

Rosa Luxemburgo ganha importância no modelo contra-hegemônico de democracia e participação. Para a autora, somente com a consciência de classe, que para ela, é considerada como "exame da terrivel gravidade, de toda a complexidade de tarefas a cumprir, da maturidade política e da autonomia intelectual, da capacidade de julgamento crítico das massas, abafadas ao longo de décadas pela socialdemocracia alemã" (Luxemburgo 1991, 65), é que será possivel fazer com que o proletariado realize ações históricas.

A autora argumenta sobre a inviabilidade de considerar o direito ao voto um produto desligado da realidade social, sendo necessário, conforme a autora, uma relação constante entre o povo e o governo, entre o eleito e o eleitorado, pois o voto é objeto momentâneo, desligado da realidade social, que está em constante mudança. Argumenta ser necessária a atuação precisa das massas, exercendo forte influência na tomada de decisão pelo representante (Luxemburgo 1991).

De contribuição também relevante para o modelo contra-hegemônico, Carole Pateman (1992) em seu livro Participação e Teoria Democrática, analisa o papel da participação em uma teoria da democracia moderna. No primeiro capítulo, a autora utiliza como pontos de partida autores liberais da democracia moderna, para defender sua teoria, exercendo o contraponto aos modelos hegemônicos. Para ela, os procedimentos democráticos devem se expandir para além do Estado, vinculando a vivência cotidiana à educação política. Ainda, especialmente no local de trabalho é que se deve democratizar a vida cotidiana, contribuindo com o ganho de mais controle sobre a vida cotidiana do indivíduo, havendo uma retomada coletiva da autonomia. Um segundo elemento defendido por Pateman é a educação política, que seria resolvida com a participação direta nos locais da vida cotidiana (Pateman 1992).

Pateman (1992) ao mencionar Schumpeter (autor liberal), afirma que o autor era a favor de alguns requisitos necessários para a participação do indivíduo. Ele acreditava que a competição entre os líderes pelos votos constituia o elemento democrático característico desse método. 0 autor Berelson (1954), segundo Pateman (1992), também afirma serem necessárias algumas condições para que a democracia sobreviva: limitar o conflito, restringir a taxa de câmbio, manter a estabilidade social e econômica, organização social e pluralista e consenso básico. Ele afirma que os autores básicos falam de uma sociedade homogênea, mas que o que se encontra seria a heterogeneidade. Ainda, os altos niveis de participação são exigidos apenas de uma minoria e o desinteresse da maioria cumpre papel na estabilidade. Mas Berelson não coloca as características necessárias para um sistema ser democrático. Ao citar Dahl (1965), Pateman afirma que ele 
encara as teorias que critica como inadequadas para hoje e sua teoria (poliarquia - governo de múltiplas minorias) como adequada. Dahl também considera os pré-requisitos para estar apto a participar. O mais radical citado por Pateman é Sartori (1962). O medo de que a participação leve ao totalitarismo permeia o pensamento de Sartori. Conforme o autor, o autogoverno somente ocorreria em momentos revolucionários e por um curto período de tempo. O autor ainda acrescenta que não devemos esperar até ocorrerem os desastres provocados por uma utopia para que reconheçamos a existência do impossivel, corroborando para o questionamento de saber como os ideais se transformam em realidade, em que sentido e com que resultados. Embora defenda o governo democrático, o autor argumenta a favor de uma limitação, a favor da representação, pois considera o autogoverno, conforme citado anteriormente, como utópico. Para Sartori, as eleições, são um meio para um fim, que é um "governo de opinião", no qual o governo é sensivel e responsável perante a opinião pública. Salienta que as eleições servem para decidir sobre quem vai decidir. Mas também ressalta a necessidade de levar em conta a pobreza da opinião pública e também as simplificações que ocorrem nas eleições. Entretanto, afirma que, apesar das dúvidas sobre a prática, a teoria ainda passa muito bem, uma vez que nada do que postula é contrariado pelos fatos (Schumpeter 1961; Dahl 1989; Pateman 1992; Sartori 1994). O último autor citado por Pateman (1992) é Eckstein (1966). O pensamento de Eckestein se baseia na questão da estabilidade. Para ele, é necessário que os elementos da sociedade estejam próximos do governo, ou seja, o padrão de autoridade do governo deve ser congruente com a sociedade.

Ellen Wood (2003) também se apropria de teses liberais para demonstrar que todas as formas de democracias liberais não passam da ressignificação de valores sociais. Ela compara a democracia antiga e a democracia moderna. Como democracia antiga, ela cita a ateniense, onde o cidadão afirma não ter senhor, não ser servo de nenhum homem mortal. A divisão entre proprietários governantes e súditos camponeses constituiu a soberania popular, que surgiu no início da Europa moderna. Já na democracia moderna, a figura representativa é o barão feudal, onde surge o senhorio, o capitalismo liberal. Assim, com a soberania popular, o significado é outro, pois o "povo" é um estrato privilegiado - a nação política situada entre a monarquia e a multidão.

Igualmente, ao analisar a democracia norte-americana, Wood (2003) afirma que seus fundadores não a queriam de fato. Para ela, os federalistas se esforçaram para mudar o foco da política da localidade para o centro federal. Criou-se a democracia representativa onde cada indivíduo atua isoladamente, não o social que aparece em primeiro plano. Assim, fica clara a diferença entre a democracia grega, considerada ativa e direta, em relação às democracias modernas, indiretas e passivas, onde se valoriza mais a questão econômica.

Carlos Estevam Martins (2004) segue a mesma linha, citando como exemplo o caso europeu, onde a socialdemocracia sempre pretendeu manter o núcleo capitalista, com alguns valores socialistas (economia de centro e política de esquerda), argumentando que a socialdemocracia seria superior ao Estado liberal. Comemorava-se que a socialdemocracia teria engolido o liberalismo, mas o que aconteceu foi o oposto: o liberalismo engoliu a socialdemocracia. Para ele, as "conquistas democráticas" resultaram do empenho das forças populares. Os liberais apenas as incorporaram e as implementaram a seu modo (Martins 2004). Assim, a democracia contra-hegemônica não pode ser confundida com o liberalismo.

Por fim, cabe salientar o autor Domenico Losurdo (2004), que também se utiliza de autores hegemônicos para defender sua tese. Losurdo igualmente se baseia no modelo representativo, argumentando que não representaria os interesses populares. O autor se utiliza de autores liberais, tais como Constant, Tocqueville, John Stuart Mill, Burke e Mandeville, para abordar questões como o sufrágio em dois graus, a restrição censitária dos direitos políticos, a aceitação do modelo representativo e a crença de que somente alguns indivíduos estariam aptos a participar da tomada de decisão. 
Conclui-se que a Participação Popular deve ser vista como elemento central no processo de tomada de decisão, pois é na participação plena que se realiza a partilha do poder decisório, na centralidade da participação está a realização da democracia. É necessário que os sujeitos políticos diversos tenham liberdade de expressão e deliberação capaz de influenciar, de fato, decisões públicas relevantes. Essa é a tese da democracia contra-hegemônica.

\section{Escalas de participação}

Com o objetivo de definir o grau de participação conforme dada realidade, a autora Sherry Arnstein (2002) elaborou uma tipologia, onde o grau de participação se organiza em niveis, formando uma espécie de "escada", onde cada degrau corresponde ao nivel de poder cidadão em decidir sobre os resultados.

Conforme a autora, "existe uma diferença fundamental entre passar pelo ritual vazio da participação e dispor de poder real para influenciar os resultados do processo" (Arnstein 2002, 2). Para ela, quando a participação ocorre sem redistribuição de poder, aqueles que tomam a decisão podem argumentar que todos os lados foram ouvidos, mas beneficiar apenas alguns.

Em relação à tipologia elaborada pela autora, os degraus sobem, na medida em que aumenta o nivel de participação. Tal tipologia pode ser conveniente na análise de casos concretos, a fim de verificar a ocorrência ou não de participação, em distintas realidades.

Para Sherry Arnstein (2002), participação cidadã é poder cidadão, ou seja, é a redistribuição de poder que permite aos cidadãos "sem-nada", que são os cidadãos excluidos dos processos políticos e econômicos, serem incluídos no processo:

Ela é a estratégia pela qual os sem-nada se integram ao processo de decisão acerca de quais as informações a serem divulgadas, quais os objetivos e quais as politicas públicas que serão aprovadas, de que modo os recursos públicos serão alocados, quais programas serão executados e quais benefícios, tais como terceirização e contratação de serviços, es- tarão disponiveis. Resumindo, a participação constitui o meio pelo qual os sem-nada podem promover reformas sociais significativas que thes permitam compartilhar dos benefícios da sociedade envolvente. (Arnstein 2002, 1-2)

Desse modo, Arsntein (2002) elaborou uma tipologia de oito niveis de participação dispostos em forma de uma escada, onde cada degrau corresponde ao nivel de poder do cidadão em decidir sobre os resultados, como pode ser visualizado na Figura 1.

Figura 1 - Oito degraus da escada da participação cidadã

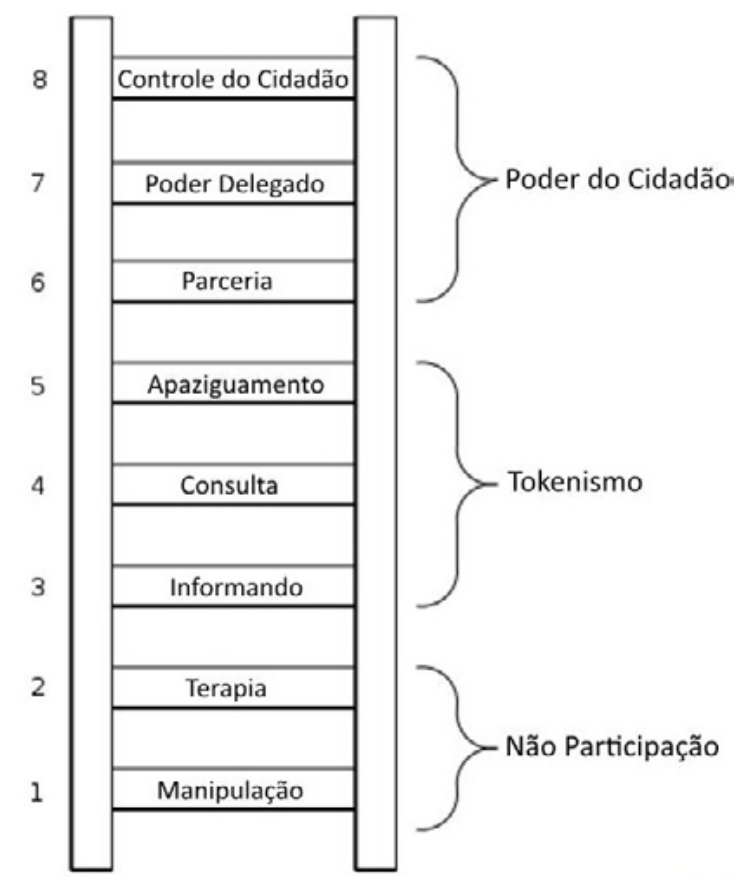

Fonte: Imagem extraída de Farnham (2014).²

Os primeiros degraus da escada (Manipulação e Terapia) descrevem niveis de não participação, que têm sido utilizados por alguns governos no lugar da genuína participação e seus objetivos não permitem que a população participe genuinamente nos processos ou conduza programas, mas permitem que os tomadores de decisão possam "educar" ou "curar" os participantes. Assim, cidadãos são convidados a participarem de comitês ou conselhos consultivos. No entanto, sem real poder de decisão. No caso da Manipulação, o propósito é educá-los ou obter seu apoio. Como

\footnotetext{
2 Kimberly Farnham, Para uma Melhor Compreensão da Participação Cidadã: A Escada da Participação de Sherry Arnstein, RioOnWatch acessado em 26 maio 2019, http://rioonwatch.org.br/?p=11602\#prettyPhoto.
} 
exemplo, podem-se citar as ACC's (Agências de Ação Comunitária), que criaram estruturas chamadas de "conselhos de bairros" ou "grupo consultivo do bairro", que são realizados com o intuito de demonstrar que "pessoas da base" estão envolvidas no processo. Entretanto, objeto de discussão, na prática, não é apresentado ao povo, ou o é de forma superficial, seguido de votação, não havendo uma compreensão exata do processo, por parte do povo. Contudo, isso pode contribuir para que alguns cidadãos aprendam as regras do jogo e comecem a jogar eles mesmos, exigindo niveis genuinos de participação. No caso da Terapia, quem a aplica, geralmente profissionais da psicologia ou do serviço social, parte do pressuposto de que a falta de poder é sinônimo de distúrbios mentais, ou seja, o foco está em curá-las de suas "patologias", ao invés de mudar o racismo e a violência que originaram suas patologias. Sob o manto ilusório de envolver os cidadãos no planejamento, os especialistas submetem as pessoas à terapia grupal. Como exemplo, podem ser citados casos que ocorrem em conjuntos de habitação popular, nos quais grupos de moradores são treinados para a realização de campanhas de controle de violência ou limpeza, para "ajustar seus valores aos da sociedade" e, assim, os moradores acabam não se ocupando de temas mais importantes, como remoção ilegal de invasões, segregação social no conjunto habitacional, ou razões pelas quais, durante o inverno, o conserto de uma janela quebrada demora três meses (Arnstein 2002, 4-6).

Os degraus três e quatro (Informação e Consulta) demonstram um avanço, no sentido de que o cidadão comum, através dessas duas ferramentas, pode ouvir e ser ouvido pelo governo, mas não há garantia para que suas opiniões sejam aceitas por aqueles que detêm o poder. Em relação à Informação, informar os cidadãos seria um passo fundamental no caminho de uma participação legítima. No entanto, a ênfase costuma estar na mão única da informação, havendo baixa possibilidade de influência popular no que é estabelecido. Como exemplo, pode-se citar notícias, panfletos, pôsteres e pesquisas de opinião. Ainda, os cidadãos podem sentir-se intimidados pelo linguajar da informação, o que pode contribuir para o aceite da informação, sem um debate anterior. Em relação à Consulta, se ela não estiver integrada com outras formas de participação, não oferece nenhuma garantia de que os anseios dos individuos serão levados em consideração, pois as pessoas são vistas como abstrações estatísticas e a participação é medida pelo número de pessoas presentes nas reuniões. Em outras palavras, os cidadãos "participaram da participação", e o que os implementadores conseguiram foi "envolver" determinado número de pessoas. Os instrumentos mais utilizados para consultar a população são pesquisas de opinião, assembleias de bairro e audiências públicas (Arnstein 2002).

O degrau cinco, Pacificação, constitui um nível superior, pois permite ao cidadão comum "aconselhar" os poderosos, mesmo que detenham o direito de tomar a decisão final. Conforme e autora, "é a partir deste nivel que os cidadãos passam a ter certa influência, mesmo que o acesso ao poder seja ainda limitado" (Arnstein 2002, 8). Um exemplo de Pacificação que pode ser dado é quando se coloca alguns cidadãos "confiáveis" em órgãos colegiados, como os conselhos estaduais, municipais e federais. No entanto, se tais individuos não tiverem sido escolhidos pela população e, ainda, se forem minoria, em relação aos tomadores de decisão, eles podem ser sobrepujados.

A partir do sexto degrau, Parceria, pode-se verificar mudanças significativas no que se refere ao aumento da participação por parte do cidadão comum. No sexto degrau, os cidadãos podem participar de uma parceria que lhes permita negociar de igual para igual com os que detêm o poder. Conforme a autora:

Ambos os lados concordam em compartilhar o
planejamento e as responsabilidades de toma-
da de decisão através de estruturas, tais como
conselhos paritários, comitês de planejamento
e mecanismos de solução de conflitos. Após a
definição de regras básicas através de algum
tipo de tomalá-dá-cá, elas não podem mais ser
modificadas unilateralmente. (Arnstein 2002,11)

Para o melhor funcionamento da Parceria, é necessário que se tenha uma efetiva organiza- 
ção popular pressionando as lideranças a prestar contas de seus atos. No entanto, tal dinâmica só funcionaria de fato se a organização comunitária dispusesse de recursos financeiros para pagar às lideranças algum tipo de compensação pelo seu trabalho, e quando a organização tivesse os recursos para contratar seus próprios técnicos, advogados e agentes de desenvolvimento. Caso tais pressupostos fossem garantidos, os cidadãos teriam capacidade real de influenciar os resultados do plano, ou seja, "entrar na prefeitura com o chapéu na cabeça ao invés de carregá-lo na mão" (Arnstein 2002, 10-12). Como exemplo, pode-se citar uma parceria com a prefeitura, que ocorreu em um bairro pobre da Filadélfia. Quando os presentes foram solicitados a aprovar a proposta, protestaram por não terem sido consultadas anteriormente, na elaboração do projeto (que possuía 400 páginas). Assim, uma liderança dos moradores ameaçou organizar protestos caso a prefeitura não concordasse em dar aos cidadãos um prazo para a revisão do documento e apresentação de sugestões de melhorias. A prefeitura concordou e, no encontro seguinte, os moradores apresentaram um capitulo referente à participação dos cidadãos, modificando as diretrizes de uma função apenas consultiva para um forte compartilhamento de poder deliberativo, que foi incluido no projeto. Logo, o comitê foi reestruturado, permitindo que 5 dos 11 conselheiros fossem representantes da sociedade civil, culminando em um contrato de mais de US\$ 20.000/mês, permitindo o fortalecimento das organizações comunitárias, pagar às lideranças US\$ 7 por reunião pelos seus serviços e pagar os salários de agentes comunitários, urbanistas e outros técnicos de assessoria aos moradores. Ainda, tal conselho propõe iniciativas para a prefeitura, podendo vetar planos apresentados pela Câmara Municipal se não tiverem sido revisados anteriormente. Apesar da Câmara ter o poder final de veto sobre os planos, o Conselho acredita dispor de uma organização comunitária que lhe permite negociar com a Câmara (Arnstein 2002, 10-12).

No sétimo e oitavo degrau, o cidadão comum detém a maioria nos fóruns de tomada de decisão, ou ainda, o completo poder gerencial. No caso do sétimo degrau, Delegação de Poder, os cidadãos têm em mãos as principais cartas do jogo, o que pode garantir que o programa atenda aos interesses da comunidade e as divergências com os que detêm o poder podem ser resolvidas de forma negociada. Conforme a autora, um exemplo de delegação de poder é o seguinte:

\begin{abstract}
No municipio de New Haven, os moradores do bairro Hill criaram uma organização comunitária à qual foi delegada a elaboração de todos os planos do Programa de Cidades-Modelo. A prefeitura, que recebeu um repasse a fundo perdido de US\$ 117.000 do ministério para as ações de planejamento, subcontratou a organização comunitária por US\$110.000 para que esta contratasse seus próprios técnicos e consultores. A Corporação Comunitária do Bairro Hill ocupa 11 assentos dos 21 no conselho da Agência Municipal Demonstrativa, o que lhe garante a maioria dos votos quando os seus planos são revisados pela Agência. (Arnstein 2002, 12-13)
\end{abstract}

No que se refere ao oitavo degrau, Controle Cidadão, os moradores poderiam gerir um programa público ou uma organização, assumindo a responsabilidade pela definição das ações e aspectos gerenciais. Conforme a autora:

O modelo mais definido é o de uma corporação comunitária que tenha acesso direto à fonte de financiamento sem precisar de intermediários. Um pequeno número destas corporações já está produzindo bens ou serviços públicos. Diversas outras estão em fase inicial, e novos modelos de controle irão certamente surgir na medida em que os sem nada pressionarem por um maior grau de autonomia em suas vidas (Arnstein 2002, 13).

Por óbvio, a visualização dos degraus é bastante simplificada, mas de todo modo, ajuda a ilustrar a questão que se passa desapercebida: existem graus bastante diferentes de participação cidadã (Arnstein 2002).

\section{Participação Popular no Brasil: uma ferramenta em construção}

A democracia brasileira, que opera nos moldes do modelo representativo, tem sua formalização com o movimento de redemocratização, que se inicia após o fim da ditadura militar de 1964-1985. dando início a uma série de mudanças, regulamentadas pela Constituição Federal de 1988, 
que define em seu artigo 14 os instrumentos de soberania popular:

\author{
Art. 14. A soberania popular será exercida pelo \\ sufrágio universal e pelo voto direto e secreto, \\ com valor igual para todos, e, nos termos da \\ lei, mediante: \\ I - plebiscito; \\ II - referendo: \\ III - iniciativa popular. (Brasil 1988)
}

No caso brasileiro, considera-se plebiscito como uma consulta prévia à população, a respeito de determinado assunto. Já o referendo, que também é uma consulta, ocorre de forma posterior à prática de um ato estatal. Ainda, a iniciativa popular, consiste na apresentação de um projeto de lei à Câmara dos Deputados, com assinatura de, no minimo, um por cento do eleitorado nacional, distribuído pelo menos por cinco Estados, com não menos de três décimos por cento dos eleitores de cada um deles. Tais instrumentos foram regulamentados através da Lei n. ${ }^{\circ}$ 9.709, de 18 de novembro de 1998 (Brasil 1998).

No caso do plebiscito e do referendo, cabe salientar que não há vinculação direta com a tomada de decisão. O texto legal utiliza o termo "consulta" e também menciona, em seu artigo 49 que somente o Congresso Nacional pode autorizar referendo e convocar plebiscito (Brasil 1998).

No que tange à iniciativa popular, o caso é semelhante. A população pode apresentar o projeto de lei. No entanto, ele ainda será submetido ao Legislativo. O que se verifica é que em 30 anos, o congresso aprovou apenas quatro projetos de iniciativa popular (Lei n. ${ }^{\circ}$ 8.930/1994: o caso Daniella Perez, Lei n. 9.840/1999: combate à compra de votos, Lei n. ${ }^{\circ} 11.124 / 2005:$ moradia popular e Lei Complementar n. ${ }^{\circ}$ 135/2010: a Lei da Ficha Limpa). Além disso, nenhum dos projetos foi reconhecido, do ponto de vista formal como sendo de autoria da população, mostrando a fragilidade de tal instrumento de participação.

Como se pode perceber, o recall e o veto popular não estão inseridos nos dispositivos legais referentes às formas de exercer o sufrágio universal. Entretanto, tais ferramentas serão citadas no trabalho por três motivos:
1. Como foi observado, os mecanismos de Participação Popular inclusos na Constituição Federal de 1988 não englobam a participação direta, pois a decisão final é do Legislativo.

2. O veto popular e o recall já foram objetivos de Projetos de Lei, apesar de não terem sido aprovados.

3. O veto popular e o recall constituiriam verdadeiros mecanismos de participação direta, conforme será sintetizado a seguir.

No que se refere ao veto popular, a ausência de tal mecanismo nas democracias contemporâneas dificulta a conceituação do dispositivo. Entretanto, faz-se necessário enfrentar o tema (Dasso Junior 2017).

Por isso, a primeira constatação é de que o veto popular combina elementos da iniciativa popular e do referendo. O veto popular é um elemento da democracia direta, pois permite que os individuos, mediante determinado número de assinaturas, bloqueiem uma iniciativa legislativa, de modo geral, antes que transcorra um período de tempo, ou seja, o povo tem a possibilidade de se manifestar de forma contrária a uma medida ou lei, já devidamente elaborada e em vias de ser posta em execução. A aprovação popular é uma condição necessária para a lei entrar em vigor, consistindo em três etapas: o órgão legislativo aprova uma lei que não entra em vigor de imediato, o povo solicita que a lei seja submetida à sua manifestação e, por fim, se a recusa for majoritária, a lei não subsiste (Dasso Junior 2017).

Por fim, o recall consiste na possibilidade dos cidadãos revogarem o mandato político de determinado representante, caso estejam insatisfeitos com sua atuação. Faz-se, então, uma consulta à opinião pública, solicitada por determinado número de eleitores, para que seja decidido se o candidato eleito deve permanecer ou ser destituído do seu cargo, com o direito de o impugnado apresentar ampla defesa em favor da manutenção do seu mandato político. O recall tem origem na legislação dos Estados Unidos. Foi introduzido em 1903 na Carta de Los Angeles por Theodore Roosevelt, fazendo parte 
do programa do "movimento progressivo". O art. 71 da Constituição de Weimar dispunha sobre a destituição do Presidente (Richard 1988).

No Brasil, o recall aparece uma única vez no Decreto n. ${ }^{\circ} 16$ de 1822, no Brasil Império. Todavia, em todas as constituições do Brasil, na figura do recall, não há e nunca houve a sua regulamentação (Santos e Campodonico 2017).

Apesar de não estarem previstos na Constituição Federal de 1988, o recall e o veto popular já foram objetos de projetos de lei, como a PEC n. 80 de 2003, que altera o artigo 14 da Constituição Federal de 1988, inserindo o direito de revogação e o veto popular como mecanismos de democracia participativa e a PEC n. ${ }^{\circ} 73$ de 2005, que acrescenta o artigo 14-A, instituindo o referendo revocatório do mandado do chefe do Executivo e de Congressista. ${ }^{3}$

\section{Escalas de Participação Popular: o caso brasileiro}

Após a revisão da literatura sobre o tema e a análise dos dispositivos legais (Constituição Federal de 1988, leis e projetos de lei), foi realizado o cruzamento dos dados, na tentativa de enquadrar os mecanismos de participação - plebiscito, referendo, iniciativa popular, recall e veto popular - nas escalas preconizadas por Arnstein, com o intuito de visualizar em que degrau de participação se encontram tais instrumentos.

Posteriormente à análise, chegou-se à conclusão de que o plebiscito e o referendo, mesmo com as limitações que possuem na forma como são regulamentados no Brasil, possuem características de consulta (nivel quatro) e delegação de poder (nivel sete). Ou seja, transitam entre uma concessão mínima de poder, se aproximando, moderadamente, de algum poder decisório. Se a regulamentação desses instrumentos fosse realizada de outra forma, não cabendo a decisão final ao Legislativo, e sim à população, poderiam estar completamente no nível sete (delegação de poder).
Quanto à iniciativa popular, do ponto de vista teórico, nenhum dos degraus corresponde exatamente ao que temos no Brasil. Entretanto, poderiamos pensar que possui algumas características que a aproximam de uma "espécie" de parceria (nivel seis), como a elaboração de um projeto de lei, por parte da população, bem como o fato de que tal lei pode partir da população. Entretanto, não configura avanços, considerando que a decisão final cabe ao Legislativo.

A respeito do veto popular e do recall, apesar de não estarem regulamentados no caso brasileiro, pode-se chegar à conclusão de que são os que mais avançam no sentido de poder decisório popular, tendo em vista que a população teria o poder de vetar uma lei antes de sua vigência, no caso do veto popular, e de destituir um representante de seu mandato, no caso do recall. Assim, admite-se que o recall e o veto popular avançam nos niveis de participação, ficando ambos enquadrados nos niveis sete (delegação de poder) e oito (controle cidadão).

Isso posto, questiona-se por qual motivo o veto popular e o recall, apesar de já postos em discussão, não figuram no rol de instrumentos mencionados na Constituição Federal de 1988. Para responder a essa questão, salienta-se o contexto imediatamente posterior à elaboração da Constituição Federal de 1988 e à criação do PDRAE (Plano Diretor da Reforma do Aparelho do Estado), onde se pretende adequar o modelo de Estado brasileiro ao projeto neoliberal, ressignificando os conceitos de sociedade civil, participação e cidadania, que estavam previstos na Constituição, conforme citado na introdução do trabalho.

\section{Considerações finais}

A partir da análise dos instrumentos de participação e do referencial teórico, já é possivel verificar os primeiros resultados. ${ }^{4}$ Fica visivel o déficit democrático no caso brasileiro, onde os

\footnotetext{
3 Eduardo Suplicy. Proposta de Emenda à Constituição n 73. de 2005. Senado Federal - Atividade Legislativa. s.d. Acessado em 29 maio 2019. https://www25.senado.leg.br/web/atividade/materias/-/materia/76146.

4 Este estudo faz parte de uma pesquisa em andamento, no âmbito do grupo de pesquisa Gedap (Grupo de Pesquisa em Estado, Democracia e Administração Pública), que tem como eixo principal de estudo a temática da Participação Popular e o controle social e seus impactos na América Latina, sobretudo, no periodo imediatamente posterior às ditaduras militares e, adicionalmente, após as reformas realizadas para adequação ao modelo neoliberal.
} 
instrumentos de Participação Popular vigentes foram regulamentados a menor, com ressalvas, deixando a decisão final, na maioria das vezes, a cargo do Poder Legislativo e considerando a Participação Popular, na maioria dos casos, apenas como uma forma de consulta. Tal elemento se confirma pelo fato de tais instrumentos não se enquadrarem, do ponto de vista teórico, em niveis mais avançados de participação.

Aliás, a não regulamentação de dois instrumentos poderosos de Participação Popular também demonstra que não há entusiasmo, por parte do Estado, sobretudo a partir do contexto em que nos deparamos a partir da década de 1990, em promover o estímulo de tal iniciativa. Desse modo, sugere-se para estudos posteriores uma comparação mais detalhada do instrumento de participação com o contexto de reformas iniciado a partir da década de 1990 para adequação ao modelo neoliberal.

Assim sendo, conclui-se a necessidade do aumento de participação da sociedade civil e, também, do Estado. A primeira, pressionando os governos por mais espaço no processo decisório. O segundo, estimulando o aumento da participação e, sobretudo, a eficácia de seus instrumentos, para que Estado e sociedade civil possam trabalhar juntos na construção das políticas públicas.

\section{Referências}

Arnstein, Sherry R. 2002. Uma escada da participação cidadã. Acesso Junho 14, 2018.http://disciplinas.stoa. usp.br/pluginfile.php/8464/mod_resource/content/1/ escada_de_participacao.pdf.

Brasil. 1988. Constituição da República Federativa do Brasil. Brasilia. Acesso Junho 19, 2018. http://WwW. planalto.gov.br/ccivil_03/constituicao/constituicaocompilado.htm.

Brasil. 1998. Lei no 9.709, de 18 de novembro de 1998. Lei da soberania popular. Brasília. Acesso Junho 19, 2018. http://www.planalto.gov.br/ccivil_03/leis/lg70g.htm.

Brasil, Presidência da República. 1995. Plano Diretor da Reforma do Aparelho do Estado. Brasília: Presidência da República, Câmara da Reforma do Estado, Ministério da Administração Federal e Reforma do Estado, 1995.

Dagnino, Evelina. 2004. "Construção democrática, neoliberalismo e participação: os dilemas da confluência perversa". Politica \& Sociedade - Revista de Sociologia Política. Florianópolis, v. 1(5): 137-161.
Dahl, Robert A. 2001. Sobre a democracia. Tradução de Bcatriz Sidou. Brasilia: Editora Universidade de Brasilia.

Dasso Junior, A. E. 2017. O Veto Popular na América Latina. Trabalho preparado para apresentação no $9^{\circ}$ Congresso Latinoamericano de Ciência Política, organizado pela Associação Latino-americana de Ciência Política (ALACIP). Montevideo, 26 a 28 de julho de 2017.

Losurdo, Domenico. 2004. Democracia ou Bonapartidarismo: triunfo e decadência do sufrágio universal. Tradução de Luiz Sérgio Henriques. Rio de Janeiro: Editora UFRJ / Editora UNESP

Luxemburgo, Rosa. 1991. A revolução russa. Introdução, tradução e notas de rodapé de Isabel Maria Loureiro. Petrópolis, RJ: Vozes.

Martins, Carlos Estevam. 2003. Liberalismo: o direito e o avesso. DADOS - Revista de Ciências Sociais, 46(4): 619-66o. https://doi.org/10.1590/So01152582003000400001

Pateman, Carole. 1992. Participação e teoria democrática. Rio de Janeiro: Paz e Terra.

Richard, Lionel. 1988. A República de Weimar (1919-1933). São Paulo: Cia das Letras

Honorato, Carlos e Thais Recoba Campodonico. 2017 O Recall politico na América Latina. Trabalho preparado para apresentação no $9^{\circ}$ Congresso Latinoamericano de Ciência Política, organizado pela Associação Latino-americana de Ciência Política (ALACIP). Montevideo, 26 a 28 de julho de 2017.

Tocqueville, Alexis de. 2005. A democracia na América leis e costumes de certas leis e certos costumes politicos que foram naturalmente sugeridos aos americanos por seu estado social democrático. Tradução de Eduardo Brandão; Prefácio, bibliografia e cronologia de François Furet. 2 ed. São Paulo: Martins Fontes.

Wood, Ellen Meiksins. 2003. "O demos versus "nós, o povo": das antigas às modernas concepções de cidadania". In Democracia contra capitalismo: a renovação do materialismo histórico, 177-204. São Paulo: Boitempo.

\section{Bruna Hamerski}

Graduada em Administração Pública pela Universidade Federal do Rio Grande do Sul (UFRGS), em Porto Alegre, RS, Brasil; mestranda em Ciências Sociais pela Pontificia Universidade Católica do Rio Grande do Sul (PUCRS), em Porto Alegre, RS, Brasil. 